\title{
COMPARTE, COPIA Y MEJORA: LA PIRATERÍA COMO MEDIO DE DESARROLLO TECNOLÓGICO Y CULTURAL
}

\author{
Pablo Martínez Garrido \\ Investigador independiente
}

\section{Resumen}

Esta ponencia pretende hablar de la piratería no tanto como una amenaza al sistema, sino como la manera más eficaz de desarrollo tecnológico y cultural. Partiremos de los ejemplos mencionados en The Pirate Book (Maigret \& Roszkowska 2015). Primero, el caso de la industria shanzhai en China, cuya deficiencia educativa de los trabajadores les ha llevado a aprender por sí solos los conocimientos técnicos que compiten con la industria tecnológica occidental. El trabajo para las compañías internacionales les permite reproducir a la perfección estos productos y ponerlos en circulación. Luego, el caso de El Paquete, el principal medio de difusión cubano; una carpeta repleta de material audiovisual que puedes descargar en un pendrive en establecimientos físicos. Este material suele estar prohibido por el gobierno de Cuba, que lo tacha de inmoral (series americanas, últimos estrenos, libros, música reggaetón, software e incluso una versión offline de Wikipedia que se refresca con cada actualización semanal del Paquete). Por último, el caso de la industria cinematográfica llamada Mollywood, ubicada en una ciudad pobre de la India llamada Malegaon. Partiremos de un documental que sigue el rodaje de una versión de Superman realizada con recursos muy escasos.

Palabras clave: PIRATERÍA; DESARROLLO; TECNOLOGÍA; CULTURA; POLÍTICA

\section{SHARE, COPY AND IMPROVE: PIRACY AS A MEANS OF TECHNOLOGICAL AND CULTURAL DEVELOPMENT}

\begin{abstract}
This paper aims to talk about piracy not so much as a threat to the system, but as the most effective way of technological and cultural development. We will set out from the examples mentioned in The Pirate Book (Maigret \& Roszkowska 2015). First, the instance of the Shanzhai industry in China, whose educational deficiency of workers has led them to learn by themselves the technical knowledge that competes with the Western technology industry. The work for international companies allows them to reproduce these products perfectly and putting them into circulation. Then, the example of El Paquete, the main Cuban media; a folder full of audiovisual material that you can download on a flash drive in physical establishments. This material is usually forbidden by the Cuban government, which calls it immoral (North American series, latest blockbusters, books, reggaeton music, software and even an offline version of Wikipedia that is refreshed with each weekly update of the package). Finally, the case of the film industry called Mollywood, located in a poor city in India called Malegaon. We will set out from a documentary that follows the filming of a version of Superman made by very few resources.
\end{abstract}

Key words: PIRACY; DEVELOPMENT; TECHNOLOGY; CULTURE; POLITICS.

\footnotetext{
Martínez Garrido, Pablo. 2018. "Comparte, copia y mejora: La piratería

como medio de desarrollo tecnológico y cultural“. AusArt6(2): 103-112.

DOI:10.1387/ausart.20355
}

\section{AUSART}




\section{INTRODUCCIÓN}

Si buscamos piratería en Google, las principales entradas remiten al aspecto judicial punitivo: cursos de formación de abogados contra piratería, nuevas leyes y penas, noticias sobre procesos... Y es que para éste análisis debemos asumir que la palabra piratería es en sí una designación peyorativa, principalmente motivada por las grandes industrias, prensa y legisladores. No obstante, el uso de la palabra ha sido reapropiada como emblema de los movimientos y proyectos a favor de su uso; como el portal The Pirate Bay o el mismo Movimiento Pirata, base de la creación de los Partidos Pirata asentados en varios países ${ }^{1}$.

El fin de este artículo es tomar la piratería como una actitud propia de la era de la información. Esa no es otra que la del hacker, el cual no es necesariamente un informático. Tal como señala Eric $\mathrm{S}$. Raymond en su famoso artículo ¿Cómo ser un hacker?: "La mentalidad de hacker no está confinada a esta cultura de hackers en software. Hay personas queaplican la actitud de hacker a otras cosas, como electrónica o música -- de hecho, puedes encontrarla en los más altos niveles de cualquier ciencia o arte" ${ }^{2}$ (Raymond 2017).Yendo al campo que nos incumbe, esta definición encaja perfectamente con el proceso investigador que conllevan las prácticas artísticas.

Si queremos un análisis más económico, una publicación muy interesante es Media Piracy in Emerging Economies de Joe Karaganis. En él, Karaganis desglosa una buena cantidad de estudios sobre las pérdidas que la piratería suponen a la industria y los rebate parte por parte. En resumen, explica que la inmensa mayoría de estudios realizados están patrocinados por las compañías multinacionales y que, sin duda, vierten una larga sombra sobre esta práctica. Los estudios no son realistas pues no existe forma de contabilizar cuánta piratería hay, y también es difícil calcular cuántas ventas se habrían realizado de no ser por la existencia de la piratería. Pero tal vez uno de los argumentos más fuertes sea éste: "la piratería local puede traerle pérdidas a sectores industriales especificos, pero éstas no resultarían pérdidas para la economía nacional más extensa. Dentro de un país, la piratería de bienes locales es una transferencia de ingresos, no una pérdida. El dinero que ahorran los consumidores o las empresas en CD, DVD o software no desaparece sino que suele ser utilizado en otras cosas (...). Estos gastos, a su vez, generan ingresos por impuestos, nuevos empleos, inversiones en infraestructura y una lista de otros bienes que los análisis de la industria colocan habitualmente en la columna de pérdidas" (Karaganis 2011, 18). 
En conclusión, si bien el análisis de la parte buena de la piratería daría para una investigación intensa, vamos a comentar a continuación tres casos relevantes en los que la piratería ha supuesto la manera más viable al desarrollo. Los tres casos han sido inspirados por el libro The Pirate Book (Maigret \& Roszkowska 2015) el cual ha sido el referente principal de este artículo.

\section{EL MODELO SHANZHAI CHINO}

China es quizás el caso más paradigmático en el que la piratería ha sido beneficiosa tanto para el mercado local como para el global. Y de entre todas las urbes destacadas por su capacidad industrial, el caso más brillante es la ciudad portuaria de Shenzhen, ubicada en el delta del río de las Perlas. Ésta zona fue una de las primeras en abrirse al comercio exterior. En los años 80, época en el que la escolarización era prácticamente inexistente, muchísimas compañías occidentales acudieron a la ciudad para contratar mano de obra barata. La idea era convertir granjeros analfabetos en trabajadores habilidosos capaces de fabricar productos de última generación.

Aunque muchas compañías acabaron abandonando China por la escasa calidad en el resultado, no esperaban lo que la especialización de los trabajadores iba a ocasionar. En la China de entonces, un trabajador que cosía zapatillas para Adidas durante el día, cosía zapatillas para él mismo durante la noche. Es decir, si sabes fabricar alta gama para una compañía, sabes cómo competir contra ella. "Cuando no tienes recursos, un sistema educativo apropiado ni mentores a tu disposición, aprendes de tu supervivencia. Copias, pegas, reproduces, modificas, te esfuerzas (y ocasionalmente mejoras)" 3 (Renaud 2015, 125).

Son famosos los casos en los que la retroingeniería aplicada con el fin de saber fabricar con menores costes, han disparado la industria local china. Se ha desarrollado una verdadera industria de la fabricación que las compañías occidentales detestan, pues son capaces de imitar a la perfección un móvil Samsung y además mejorarlo. Por ello, la mayoría de compañías suele comprar los teléfonos a estas fábricas, a los cuales se les añade posteriormente las especificaciones de marca. Esta industria tiene un apodo: Shanzhai. "En la cultura popular china, Shanzhai (shan: montaña, zhai: fortaleza) se refiere a un 
pueblo alejado en las montañas donde los bandidos recreaban su propia forma de sociedad, alejada de las normas del emperador"4 (Ibíd., 123).

Shanzhai es todo un fenómeno en la sociedad China, una forma de ser y de ver el mundo. Culturalmente, la mentalidad shanzhai se enfoca en imitar a la perfección un producto de consumo con un toque irónico. En cuanto a productos tecnológicos se pueden encontrar teléfonos móviles con un mechero incorporado o un compartimento donde guardar los cigarrillos. En textiles, las archiconocidas marcas de imitación como Adobos, Dolce Camino o Like. Toda una aberración para los defensores de la identidad corporativa, ¿pero dónde queda la falsificación, cuando estas marcas fabrican con los mismos materiales, la misma ciudad y muy probablemente en la misma fábrica? Para estas fábricas es posible fabricar un mismo producto con distinta calidad, desde algo que prácticamente es un chiste que se rompe nada más usarlo a un producto de altísima calidad (igual o superior que uno original).

Pero Shanzhai no se queda recluida en la industria. Afecta del mismo modo a la cultura misma y transforma los métodos de consumo. "El halago a la copia, la crisis y el mercado lowcost han propiciado un crecimiento que invierte el poder social de la logomanía por la demanda de réplicas" (Carreño 2017, 65). En China existen estrellas y programas de televisión shanzhai que a menudo se vuelven archiconocidos de la noche a la mañana hasta el punto de rivalizar con el original. También se cuenta que"frente al programa de gala organizado cada año por la Televisión Nacional de China (CCTV) para la víspera del año nuevo chino, muchos jóvenes prefieren ver las versiones shanzhai del mismo programa, que circulan por Internet. En ese sentido, la cultura shanzhai duplica paródicamente la cultura oficial, devolviéndole un reflejo distorsionado. Para estos jóvenes el shanzhai es un emblema conscientemente reivindicado, con connotaciones incluso de cierta rebeldía" (Petrecca 2013).

En cuanto al arte shanzhai, destaca la Dafen Oil Painting Village. Un suburbio de la ciudad de Shenzhen donde trabaja la mayor comunidad de pintores copistas del mundo. Dafen es un referente clave para el arte contemporáneo, pues muchísimos artistas han encontrado en China el mejor lugar para producir sus obras de la manera más económica posible, afirma Carreño, donde encargan las pinturas ya realizadas. Algo totalmente legítimo en el arte contemporáneo, donde la mano del autor ha dejado de ser una exigencia. ¿Por qué si un artista es mediocre pintando no puede usar una pintura técnicamente bien ejecutada como medio? La producción por cuenta ajena ahorra tiempo y dinero, y puede ofrecer resultados formales mucho mayores, en medida de lo que el artista 
considere oportuno. En occidente existen numerosas muestras que tratan y fuerzan este tema y que por extensión no podremos desglosar aquí, pero para más información recomiendo un vistazo al citado artículo de Montse Carreño.

\section{EL PAQUETE SEMANAL, EL MEDIO DE DIFUSIÓN LIBRE DE CUBA}

Pese a que Cuba destaca en la formación de profesionales en medicina, farmacia e informática, el acceso a Internet sigue siendo una quimera para la mayoría. Y para más inri, los pocos poseedores de un ordenador cuentan con la fuerte censura del gobierno. Según Freedom House, Cuba es uno de los países del mundo tiene menor libertad de acceso a la red ${ }^{5}$. Dado que éste es uno de los principales problemas que tienen que superar los hackers, no es de extrañar la habilidad con la que cuenta la comunidad informática cubana.

Tras la Revolución Cubana, desde 1959 las medidas de nacionalización y embargo por parte del régimen cubano han promovido serios conflictos de intereses con los EEUU. Kennedy propuso el embargo a Cuba, cerrando importantes acuerdos comerciales que la isla sólo pudo suplir con la colaboración soviética (también tuvo serias dificultades para comerciar con el resto de países americanos). Durante la Guerra Fría Cuba prosperó. Sin embargo la disolución de la URSS tuvo graves consecuencias para su economía, de quien dependía en gran medida. En un pasado más reciente, los diálogos con Barack Obama prometieron una vuelta a la estabilidad, pero Trump los está echando abajo de nuevo.

El bloqueo afecta también en el acceso a los hábitos de consumo de cultura. La sociedad cubana se las ha ingeniado para solucionar este problema y disfrutar de los productos más actuales que circulan con libertad en el mundo. Existe en la isla un sistema de archivos llamado El Paquete Semanal, el cual consiste básicamente en una carpeta de un Terabyte que contiene una gran cantidad de películas, series, software, videojuegos, imágenes, noticias, etc. La idea es que cualquier persona con un pendrive o disco duro extraíble acuda a un establecimiento donde se ofrece El Paquete. En realidad, casi cualquier tienda con un ordenador es capaz de descargarlo, aunque existen numerosas tiendas de piratería. Por $1 \mathrm{CUC}^{6}$, caro si una familia no paga a escote, si pue- 
des conectar un pendrive a la televisión puedes ver los últimos estrenos o los nuevos capítulos de tus series favoritas.

El Paquete funciona de forma offline y se actualiza cada jueves. Para muchos cubanos es habitual actualizarlo semanalmente, como quien compra una revista. De hecho, las actualizaciones más comunes se centran en una versión offline de Wikipedia y otra de Revolico. Ésta última es una web de anuncios de compra/venta, lo que podríamos comparar con el Mil Anuncios de aquí, que se ha convertido en todo un referente a través del cual la gente puede comprar y vender productos mal vistos por el gobierno. De hecho "ha estado bloqueado desde su comienzo, pero hemos estado trabajando todos estos años para que los cubanos puedan tener acceso. Se ha convertido en una cosa cultural, cuando la gente compra algo ellos piensan de Revolico como 'el mercado'. Es un lugar donde pueden encontrar lo que sea. Es donde pueden comprar cosas que el gobierno no les dejará tener", admite uno de sus creadores (Koebler 2017). Revolico fue desarrollado en España por emigrados cubanos y se asienta en EEUU. Sobrevive gracias a la capacidad de los hackers de crear un grupo de proxys y atajos DNS que dificultan el rastreo gubernamental.

Por otra parte, quienes dotan de contenido al Paquete acostumbran a burlar la burocracia. "Algunos extranjeros y gente conectada a compañías extranjeras, embajadas, o consulados tiene en sus casas antenas de satélite, y algunas personas tienen antenas ilegales también. Quizás los creadores de El Paquete son personas que trabajan para el gobierno en instituciones oficiales con un buen ancho de banda que les permite descargar vídeos largos y colecciones de música" (Oroza 2015, 143). No obstante, si alguien es descubierto vendiendo puede ser perseguido y su ordenador será confiscado. Aunque sabemos que esta medida, tanto en Cuba como en cualquier país, es ineficaz y está basada en la demostración del castigo como medio disuasorio. El gobierno ha intentado de otras maneras luchar contra este sistema. Según Oroza existe también un anti-Paquete llamado El Maletín de las mismas características que el primero, solo que el contenido es añadido por el gobierno. La premisa es que el material distribuido en El Paquete es inmoral, el material occidental que comparte muestra sexo y violencia. El gobierno creó su alternativa con un contenido más sano: en lugar de estrenos norteamericanos y discos de reggaetón, el Maletín difunde películas y libros clásicos de autores cultos. El fracaso era de esperar: el contenido aburría tanto a la población que no llegó a tener ningún éxito. Por otra parte, el anti-paquete es tan ilegal como su rival, pues todo el contenido está pirateado de la misma manera y no se ha pagado un peso por los derechos de distribución de ningún producto. 
A pesar de otros métodos de disuasión, como amenazas en televisión sobre la facilidad de infectar virus a través de El Paquete, el gobierno cubano es incapaz de reducir la influencia de su uso. De hecho, se ha convertido en uno de los principales medios de difusión de numerosos artistas y grupos de música que carecen de influencia y/o la bendición del gobierno ${ }^{8}$.

\section{MOLLYWOOD, LA INDUSTRIA INDIA DEL CINE SIN MEDIOS}

Cuenta la investigadora Ishita Tiwary cómo el vídeo supuso una revolución social en la India de los 80 hasta el punto de que los cines fueron casi desbancados por la reproducción pública de películas en bares y clubs. La industria cinematográfica criticaba muy duramente la expansión del vídeo en sí. Si bien desde el claro punto de vista económico, también desde un punto de vista moral; señalando al formato como responsable de la difusión de pornografía. Ante las críticas, el gobierno seguía abogando por la piratería en cierto sentido: "El Ministro de Información y Radiodifusión decretó la tecnología del vídeo como resultado de la expansión constante del campo científico, y que por lo tanto no era deseable detener aquél desarrollo tecnológico que poseía sus propias ventajas, no sólo para fines de entretenimiento, sino también para la educación. Reconoció que si bien el advenimiento del vídeo había afectado a los ingresos de taquilla de la industria cinematográfica, no se debía a la introducción de las cintas de vídeo en el mercado, sino al acto de la piratería de vídeo. El gobierno también declaró que había tomado una serie de pasos para frenar aquella práctica" (Tiwary 2015). Aquellas medidas, sin embargo, se limitaron a legalizar los establecimientos que reproducían vídeo mediante el cobro de impuestos, no castigaban la copia de material en sí.

En este contexto, el vídeo se ha convertido en una salida para muchos. A menudo ha sido el medio de subsistencia en los pueblos más humildes para pequeños videoaficionados que se han ganado la vida con reportajes de boda. Estos pequeños negocios dependen de la piratería, pues sus pocos ingresos les impiden adquirir material original. Las videocámaras pirateadas (provenientes de la fabricación shanzhai china) y las cintas de vídeo regrabadas son lo suficientemente baratas como para aportar beneficio al productor. 
Pero la pasión por el vídeo ha llevado a situaciones bien curiosas. En Malegaon, una ciudad a unos $270 \mathrm{~km}$ de Mumbai, se ha originado una industria cinematográfica local propia ${ }^{10}$. Su población tiene un gusto general por el cine. Son muy comunes los espacios donde la gente se reúne para ver películas de todo tipo, tanto comedias antiguas como los últimos estrenos (pocas salas pueden permitirse pagar los derechos de distribución y proyectan películas piratas). En el documental Supermen of Malegaon (Khan 2008), un making off de la película homónima, se escucha a un guionista de la ciudad: "los cines están abarrotados los viernes y los telares se cierran. Un trabajador está exhausto después de toda una semana de trabajo duro en los telares. Su mente está estumecida, así que los viernes ve una película, abandona su conciencia, y se imagina a sí mismo en la pantalla. Intercambia su realidad por fantasía" (Ibíd.). Dentro de este suplicio, otros encontraron la distracción produciendo sus propias películas. No es baladí. Estas películas, siempre rodadas con medios excesivamente pobres, se han convertido en toda una industria cinematográfica. Mollywood compite en el mercado de los más humildes con Hollywood, incluso con el propio Bollywood. Son remakes de películas famosas que devienen en parodias técnicas, al ser tan pobre su producción que resulta simpática. La película Supermen of Malegaon es tal vez una de las más representativas. Aquí Superman no es un bebé que cae en una granja estadounidense, sino un tipo flaco al que su padre envía a la Tierra, concretamente Malegaon, subido en un flotador. Al caer en la ciudad, llega frente de una señora que le ruega ayudarle a secar la ropa subiéndola por los aires. La señora es un paisano vestido de mujer, de hecho, la única mujer que sale en la película es la que interpreta a Lois. La actriz, Shafique, lo explica: "La gente aquí no deja actuar a las mujeres. Es decir, depende de la familia... de cómo es la familia. Me he dado cuenta de que aquí, francamente, las mujeres no viven" (Ibid.). Sería muy raro encontrar a una paisana en una película de Mollywood, la moral musulmana lo prohíbe. De hecho, todas las actrices se contratan en otros pueblos y ciudades.

Por otra parte, saben que las películas no van a sacarles de los telares, pero sin duda es algo que da sentido a sus vidas. Ese producto ha salido completamente desde su experiencia, nadie les ha enseñado a utilizar una cámara o a manejar un programa de edición. Shakeel Bharati, director de la película, creía que cada film occidental era producto del trabajo de una sola persona, y con eso en la cabeza se lanzó a editar. El actor que interpreta a Superman no sabe nadar y a lo largo del rodaje tiene que ser rescatado por el equipo decenas de veces. No se toma un descanso, sale corriendo del telar para ayudar a montar la escena vestido con su traje. Tal vez sea la imagen más representativa del cine de Mollywood. 


\section{CONCLUSIONES}

Con estos tres casos se ha intentado abarcar la piratería desde un punto de vista diferente al propuesto por los medios y las grandes compañías. Si bien compañías y gobiernos definen la piratería como algo maligno para la economía y la cultura, es demostrable cómo ésta práctica aporta grandes beneficios económicos, culturales y tecnológicos para ambos. Así, si quisiéramos definir la piratería sin atacarla, diríamos que es el resultado de la aplicación de la actitud hacker. Es decir, una actitud que hace capaz a un individuo de adquirir por cuenta propia los conocimientos técnicos para superar un problema. En este caso, es la dificultad de asumir los costes derivados del copyright lo que promueve la piratería. Esta actitud supone el medio más común de acceso para los países en vías de desarrollo. De hecho muchos gobiernos ignoran las legislaciones sobre derechos de autor con el fin de empujar el I+D.

\section{Referencias}

Carreño Delgado, Montse. 2017. “La potencialidad de lo falso y la cultura shanzhai”. Inmaterial 2(4)

Karaganis Joe, ed. 2011. Piratería de medios en las economías emergentes. Traducido al español por Clio Bugel y Guillermo Sabanes. New York: Social Science Research Council

Khan, Faiza Ahmad. 2008. Supermen of Malegaon. Documental. Vídeo de Youtube, 1:05:52. https://www.youtube.com/watch?v=dqRq7ZpjF0l

Koebler, Jason. 2017. "El mercado negro de Cuba es un sitio online que existe sin internet". Vice.com, 6 sept. https://www.vice.com/es latam/article/3kk9v8/el-mercado-negro-de-cuba-es-un-sitio-online-que-existe-sin-internet

Maigret, Nicolas \& Maria Roszkowska, eds. 2015. The pirate book. Ljubljana: Aksioma

Oroza, Ernesto. 2015. "El Paquete Semanal \&Marakka 2000 (Cuba)".En The pirate book, edited by Nicolas Maigret \& Maria Roszkowska, 139-67. Ljubljana: Aksioma

Petrecca, Miguel. 2013. "Shanzhai, la palabra fetiche que explica los cambios en la China de hoy". Clarín.com, 17 ene. https://www.clarin.com/ideas/shanzhai-sanzai-china-miguel-petrecca 0 S15BITsoPQx.html

Raymond, Eric Steven. 2017. "How to become a hacker". Web personal delautor. http://www. catb.org/ esr/faqs/hacker-howto.html

Renaud, Clément. 2015. "Bandits brought technology to this world-Shanzhai Culture (China)". En The pirate book, edited by Nicolas Maigret \& Maria Roszkowska, 119-37. Ljubljana: Aksioma

Tiwary, Ishita. 2015. "The first wave of media piracy: Malegaon cinema industry(India, 1980s-2000s)". En The pirate book, edited by Nicolas Maigret \& Maria Roszkowska. Ljubljana: Aksioma 


\section{Notas}

${ }^{1}$ De un modo similar a cuando la comunidad LGBTI asumió el adjetivo queer.

${ }^{2}$ Este artículo es actualizado ocasionalmente por el mismo autor en su página web. Se puede acceder al documento original en inglés y al histórico de actualizaciones aquí: http://www. catb.org/ esr/faqs/hacker-howto.html[Acceso 10 nov. 2018].

${ }^{3}$ Cita original: "when you have no resources, no proper education system, and no mentors at your disposal, then you just learn from your surroundings. You copy, you paste, you reproduce, you modify, you struggle - and you eventually improve" (Renaud 2015, 125).

${ }^{4}$ Cita original: "In Chinese popular culture, a Shanzhai (shan: mountain, zhai: stronghold) refers to a remote village in the mountains where bandits had once recreated their own form of society, far from the rules of the emperor" (Renaud 2015, 123).

${ }^{5}$ Visitar el informe en https://freedomhouse.org/report/freedom-world/2018/cuba [Acceso 10 nov. 2018].

${ }^{6}$ CUC, peso cubano convertible. Es una de las dos monedas oficiales de Cuba junto al peso cubano (CUP). Se emitió como medida a la prohibición estadounidense de usar dólares en la isla. Actualmente, el uso del CUC es más habitual en el mercado negro aunque desde 2013 se está intentando unificar ambas monedas. 1 CUC $=25,75$ CUP $=1,367 €$.

${ }^{7}$ Cita original: "Some foreigners and people connected to foreign companies, embassies, or consulates have satellite antennas in their houses, and some people have illegal satellite antennas too. Maybe the creators of El Paquete are people working for the government in official institutions with large digital bandwidth that allows downloading long videos and music compilations" (Oroza 2015).

${ }^{8}$ Como ejemplo, la artista La Diosa le dedicó una canción llamada El Paquete que puede verse aquí:https://www.youtube.com/watch?v=3rcZIGiwh-M (consultado el 10 de noviembre de 2018). Si no estásen El Paquete, no existes.

${ }^{9}$ Cita original: "The Ministry decreed that video technology is a result of the ever-expanding field of science, and it was thus not desirable to stop this new technological development which has its own advantages, not only for entertainment purposes, but for education as well. It acknowledged that while the advent of video technology affected the box office revenues of the film industry, it was not due to the introduction of video cassettes in the market but the act of video piracy. The government also stated that it had taken a number of steps to curb this practice" (Tiwary 2015).

${ }^{10}$ Conocida como Mollywood. Malegaon es una ciudad muy empobrecida y a menudo conflictiva. La mayoría musulmana y el resto hindú viven en disputa, cuyo mayor conflicto fue la explosión de una bomba en 2008 que mató a 8 personas e hirió a 80. La mayor parte de la población trabaja en los telares en unas condiciones infrahumanas. 